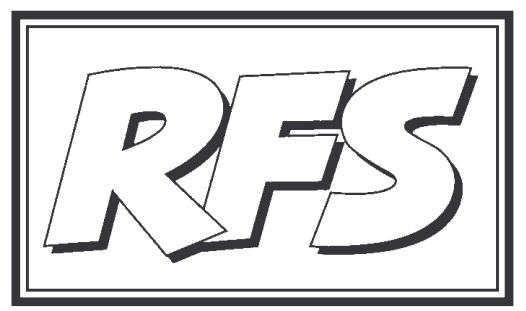

Revista de Fomento Social, 61 (2006), 9-13

\title{
La Revista de Fomento Social cumple 60 años
}

\section{Consejo de Redacción}

(PaLABRAS CLAVE: 60 anIVERSARIo ReVISTA DE Fomento Social.

KEY WORDS: 60 TH ANNIVERSARY, REVISTA FOMENTO SOCIAL)

La Revista de Fomento Social (RFS) celebra en este año 2006 su $60^{\underline{a}}$ aniver sario. El número primero corresponde a enero-marzo de 1946. Desde aquel momento, sin faltar ni una sola vez a su cita trimestral, la revista ha estado con nuestros lectores personales e institucionales (muchos de ellos fieles compañeros de camino desde entonces), convirtiendo a nuestra publicación en una de las más antiguas revistas españolas de ciencias sociales.

Si no nos equivocamos, nuestra revista es una de las pocas revistas españolas de ciencias sociales que perviven desde aquella épocal. En efecto, muy pocas

${ }^{1}$ Salvo error por nuestra parte, sólo persiste la más veterana Revista Internacional de So ciología, que nació en el Instituto Jaime Balmes del Consejo Superior de Investigaciones 
publicaciones periódicas, incluso a escala internacional, pueden presentar una hoja de servicios de esta duración, constancia y coherencia. Estas seis décadas representan para España un periodo histórico largo y complejo; la Revista ha sido testigo - a veces, más crítico, a veces, menos- del franquismo durante las tres primeras décadas; a partir de 1975 y hasta nuestros días, ha participado activamente en el debate social que acompañó en nuestro país la nada fácil transición a la democracia y el periodo posterior de normalización democrática, no exenta por cierto de sobresaltos y cambios.

Como recordarán nuestros lectores, por decisión de su responsable, el P. Provin cial de España de la Compañía de Jesús, la redacción de la Revista pasó en 1991 de la llamada "Casa de Escritores" de Madrid, donde había estado residenciada desde su fundación, a ETEA, institución universitaria de la Compañía de Jesús, en la actualidad Facultad de Ciencias Económicas y Empresariales adscrita a la Universidad de Córdoba. Precisamente en estos meses la institución que nos acoge se encuentra en trámite avanzado de pasar a integrarse en la nueva universidad Fernando III, promovida por la Provincia Bética de la Compañía de Jesús y la Fundación San Pablo (CEU) Andalucía.

Hace diez años, con ocasión de la celebración de nuestro 50 aniversario, presentamos a nuestros lectores una síntesis de la historia de la revista, así como de sus líneas de fuerza, de las personalidades que han marcado su devenir y de los rasgos más sobresalientes de su línea editoriâl Aquel cincuentenario sirvió de ocasión para hacer un balance histórico de nuestra publicación. Dividíamos el periodo en 5 etapas: a) los primeros años (1946-1953: el Padre Azpiazu); especial énfasis en las cuestiones laborales; b) años de buenas relaciones con el régimen (1954-1962); c) años de conflictos con el franquismo (1963-1974); d) en un nuevo contexto sociopolítico (1975-1990); e) en la nueva sede (Córdoba: 1991-1995). Lógicamente, diez años después, conmemoramos los 60 años de la revista.

Científicas de Madrid. Se publica desde 1943aaunque su publicación se interrumpió durante dos años (1990-1991). Es, pues, algo más antigua que nuestra RFS. Obsérvese que sus sedes tradicionales fueron vecinas durante varias décadas en las calles Serrano y Pablo Aranda de Madrid. Ahora vuelven a ser vecinas, pero en Córdoba, ya que la Revista Internacional de Sociología también se trasladó a esta ciudad un año más tarde: concretamente al Instituto de Estudios Sociales Avanzados del Consejo. Coincidencias de la historia...

2 Véase el editorial del número 200 correspondiente a enero-marzo de 1996 ("Un instrumento para la promoción de la justicia"). 
Con motivo de la celebración de aquel cincuentenario, publicamos un libro titulado Sociedad y Economía en los años 90 , que recogía la mayoría de las reflexiones editoriales publicadas entre 1991 y $1995{ }^{3}$ correspondientes a los números 182 a 198, los primeros de la etapa cordobesa de la Revista.

Más recientemente, gracias a la gentileza de la Editorial Sal Terrae, hemos reunido en un volumen titulado Sociedad, política y economía en el cambio de siglo. Reflexiones de Fomento Social ${ }^{4}$ un total de 22 artículos editoriales seleccionados de los publicados en los diez años que van de 1995 a 2004. En ese libro se aprecia claramente cuál ha sido nuestra línea editorial en los últit mos 10 años. Sus capítulos corresponden a otras tantas temáticas prioritarias: Globalización y desarrollo (Capítulo $1^{\circ}$ ), Economía mundial (Capítulo $2^{\circ}$ ), La experiencia europea (Capítulo $3^{\circ}$ ), España, las políticas gubernamentales (Capítulo 4), Ética y sociedad (Capítulo $5^{\circ}$ ).

En cuanto a los artículos publicados en estos 10 añosel 31\% trató cuestiones relacionadas con la globalización, el desarrollo, la cooperación al desarrollo y temas afines; un 25\% de los artículos abordaron temas relacionados con ética y sociedad, mercado de trabajo e ideas económicas; alrededor del 20\% se ocuparon de temas relativos a la economía mundial y a la economía y sociedad en otros países; un 10\% estuvo dedicado a la experiencia europea; un $8 \%$ trató temas relativos a nuestro país, España: políticas gubernamentales, Comunidades Autónomas, con especial referencia en algún caso a Andalucía; el resto, un 6\%, trataba temas relativos a empresa y finanzas.

Si contabilizamos los autores de este último periodo, en términos aproxi mados, alrededor de un $42 \%$ fueron profesores de ETEA; $y$ un $23 \%$ profesores de otros centros e instituciones universitarias españolas; un 11\% de autores extranjeros; un 5\% de doctorandos de nuestros programas de doctorado; asimismo contabilizamos un 7\% de documentos eclesiales (Sumo Pontífice, Conferencias Episcopales, Superior General de los jesuitas etc.) y un resto de autores varios $(11 \%)$.

3 (1995), Sociedad y Economía en los años 90. Reflexiones de la Revista de Fomento Social , Córdoba, Ed. Publicaciones ETEA, 207 pp.

4 José J. Romero (Ed.) (2005), Sociedad, política y economía en el cambio de siglo. Reflexiones de Fomento Social, Santander, Ed. Sal Terrae, 607 pp.

5 Tomamos la clasificación temática adoptada en el libro de editoriales citado en el párrafo anterior. 
Además en estos 40 números han aparecido las habituales secciones de recensiones y reseñas bibliográficas.

Con ocasión de este aniversario, se producen pequeños cambios en la Re vista. Para la evaluación de los originales, a partir de este año contaremos de forma sistemática con evaluadores externos, aunque el Consejo de Redacción se sigue reservando la última palabra sobre la composición de cada número. Otra novedad tiene que ver con la mejora y sistematización de la sección bi bliográfica. A partir de ahora los lectores encontrarán en algunos números un "estado de la cuestión" consistente en un análisis monográfico de la bibliografía básica en las áreas cubiertas por nuestra línea editorial; le acompañarán de forma habitual recensiones (largas), reseñas (cortas) y noticias de libros de posible interés para nuestros lectores. Asimismo a partir de este número, el sumario y algún artículo de la revista aparecerán en formato PDF en la página Web de ETEA. Finalmente, un próximo número aparecerá con un nuevo diseño de portada.

Por último, como pequeño gesto conmemorativo, nos permitimos reproducir a continuación en este número uno de los artículos aparecidos en el número 1 de la revista, precisamente el primer artículo después de la presentación, escrito por el ilustre economista Román Perpiñà Grau, cuyo título "¿Tiene algo que ver la economía con la ética?", resulta sumamente significativo de lo que ha intentado ser la línea editorial a lo largo de estas seis décadas.

Para terminar, son muchos los retos que una publicación como la nuestra debe afrontar en el inmediato futuro. El primero y principal es garantizar su continuidad, sin olvidar su inspiración fundante que pretende en todo momento promover y divulgar el pensamiento social cristiano, sirviendo de cauce de ex presión de análisis, posturas y opiniones diversas en el ámbito de las ciencias sociales, con una clara preocupación ética en sus orientaciones y con unos enfoques marcadamente interdisciplinares. Al fin y al cabo, como decíamos al conmemorar los 50 años ${ }^{6}$ " "la orientación última de la RFS está en función del servicio de la fe y la promoción de la justicia", en la estela de las definiciones de las últimas Congregaciones Generales de la Compañía de Jesús. Desde esa perspectiva la RFS se acerca a los "problemas relacionados con la vida social, económica y cultural, en su doble vertiente nacional y mundial".

Dado nuestro carácter universitario, hemos de consolidar y mejorar el número y la calidad de las colaboraciones, sin renunciar por ello a nuestra perspectiva

${ }^{6}$ En el ya citado número 200 (véase nota 2). 
editorial. Por otro lado, soñamos con ampliar el número de nuestros suscrip tores, pues estamos convencidos de que no hemos logrado todavía alcanzar a muchas personas e instituciones sin duda potencialmente interesados en la temática y en el espíritu de nuestra publicación.

Deseamos terminar agradeciendo a nuestros suscriptores su fidelidad, y reiterándoles nuestro deseo de contar con su apoyo permanente y sus críticas constructivas. 